\title{
Mizoguchi-Takahashi-type theorems in tvs-cone metric spaces
}

Wasfi Shatanawi', Vesna Ćojbašić Rajić ${ }^{2}$, Stojan Radenović ${ }^{3}$ and Ahmed Al-Rawashdeh ${ }^{*}$

* Correspondence:

aalrawashdeh@uaeu.ac.ae

${ }^{4}$ Department of Mathematical

Sciences, UAEU, 17551 Al-Ain,

United Arab Emirates

Full list of author information is

available at the end of the article

\begin{abstract}
In this paper, the concepts of a set-valued contraction of Mizoguchi-Takahashi type in the context of topological vector space (tvs)-cone metric spaces are introduced and a fixed point theorem in the context of tvs-cone metric spaces with respect to a solid cone is proved. We obtained results which extend and generalize the main results of S. H. Cho with J. S. Bae, Mizoguchi with Takahashi and S. B. Nadler Jr. Two examples are given to illustrate the usability of our results.
\end{abstract}

2010 MSC: 47H10, 54H 25.

Keywords: tvs-cone metric space, fixed point, Nadler's fixed point theorem, MizoguchiTakahashi fixed point theorem, locally convex space

\section{Introduction and preliminaries}

Huang and Zhang introduced in [1] the concept of cone metric spaces as a generalization of metric spaces. They have replaced the real numbers (as the co-domain of a metric) by an ordered Banach space. They described the convergence in cone metric spaces, introduced their completeness and proved some fixed point theorems for contractive mappings on cone metric spaces. The concept of cone metric space in the sense of Huang-Zhang is characterized by Al-Rawashdeh, Shatanawi and Khandaqji in [2]. Indeed $(X, d)$ is a cone metric space if and only if $\left(X, d^{E}\right)$ is an E-metric space, where $\mathrm{E}$ is a normed ordered space, with $\operatorname{Int}\left(E^{+}\right) \neq \varnothing$ ([2], Theorem 3.8). Recently in [3-28] many authors proved fixed point theorems in cone metric spaces.

$\mathrm{Du}$ in [13] introduced the concept of topological vector space (tvs)-cone metric and tvs-cone metric space to improve and extend the concept of cone metric space in the sense of Huang and Zhang [1]. In [7,9,13,14] the authors tried to generalize this approach using cones in tvs instead of Banach spaces. However, it should be noted that an old result shows that if the underlying cone of an ordered tvs is solid and normal, then such tvs must be an ordered normed space. Thus, proper generalizations when passing from norm-valued cone metric spaces to tvs-valued cone metric spaces can be obtained only in the case of nonnormal cones (for more details see [14]).

We recall some definitions and results from [14,15], which will be needed in the sequel.

Let $E$ be a tvs with its zero vector $\theta$. A nonempty subset $P$ of $E$ is called a convex cone if $P+P \subseteq P$ and $\lambda P \subseteq P$ for $\lambda \geq 0$. A convex cone $P$ is said to be pointed (or proper) if $P \cap(-P)=\{\theta\}$; and $P$ is a normal (or saturated) if $E$ has a base of

(c) 2012 Shatanawi et al; licensee Springer. This is an Open Access article distributed under the terms of the Creative Commons Attribution License (http://creativecommons.org/licenses/by/2.0), which permits unrestricted use, distribution, and reproduction in any medium, provided the original work is properly cited. 
neighborhoods of zero consists of order-convex subsets. For a given cone $P \subseteq E$, we define a partial ordering $\leqslant$ with respect to $P$ by $x \leqslant y$ if and only if $y-x \in P ; x<y$ will stand for $x \leqslant y$ and $x \neq y$, while $x \ll y$ stand for $y-x \in \operatorname{int} P$, where int $P$ denotes the interior of $P$. The cone $P$ is said to be solid if it has a nonempty interior.

In the sequel, $E$ will be a locally convex Hausdorff tvs with its zero vector $\theta, P$ is a proper, closed and convex pointed cone in $E$ with $\operatorname{int} P \neq \varnothing$ and $\leqslant$ denotes the induced partial ordering with respect to $P$.

Definition 1.1. $[7,13,14]$ Let $X$ be a nonempty set and $(E, P)$ be an ordered tvs. A vector-valued function $d: X \times X \rightarrow E$ is said to be a tvs-cone metric, if the following conditions hold:

$\left(C_{1}\right) \theta \leqslant d(x, y)$ for all $x, y \in X$ and $d(x, y)=\theta$ if and only if $x=y$;

$\left(\mathrm{C}_{2}\right) d(x, y)=d(y, x)$ for all $x, y \in X$;

$\left(C_{3}\right) d(x, z) \leqslant d(x, y)+d(y, z)$ for all $x, y, z \in X$.

The pair $(X, d)$ is then called a tvs-cone metric space.

Remark 1.2. The concept of a cone metric space [1] ( $E$ is a real Banach space and $d$ : $X \times X \rightarrow E$ satisfies $\left(\mathrm{C}_{1}\right),\left(\mathrm{C}_{2}\right)$ and $\left.\left(\mathrm{C}_{3}\right)\right)$ is more general than that of metric space, because each metric space is a cone metric space, where $E=\mathbb{R}$ and $P=[0,+\infty)$ (see [1, Example 1]). Clearly, a cone metric space in the sense of Huang and Zhang is a special case of tvs-cone metric spaces when $(X, d)$ is tvs-cone metric space with respect to a normal cone $P$.

Definition 1.3. $[7,13,14]$ Let $(X, d)$ be a tvs-cone metric space, $x \in X$ and let $\left\{x_{n}\right\}$ be a sequence in $X$. Then

(i) $\left\{x_{n}\right\}$ tvs-cone converges to $x$ whenever for every $c \in E$ with $\theta \ll c$ there is a natural number $n_{0}$ such that $d\left(x_{n}, x\right) \ll c$, for all $n \geq n_{0}$. We denote this by cone- $\lim _{n \rightarrow \infty}$ $x_{n}=x$

(ii) $\left\{x_{n}\right\}$ is a tvs-cone Cauchy sequence whenever for every $c \in E$ with $\theta \ll c$ there is a natural number $n_{0}$ such that $d\left(x_{n}, x_{m}\right) \ll c$, for all $n, m \geq n_{0}$;

(iii) $(X, d)$ is tvs-cone complete if every tvs-cone Cauchy sequence in $X$ is tvs-cone convergent.

Let $(X, d)$ be a tvs-cone metric space. The following properties are often used, particularly in the case when the underlying cone is nonnormal. The only assumption is that the cone $P$ has a nonempty interior (i.e. $P$ is a solid). For more details about these properties see [14] and [15].

$\left(\mathrm{p}_{1}\right)$ If $u \leqslant v$ and $v \ll w$, then $u \ll w$.

$\left(\mathrm{p}_{2}\right)$ If $u \ll v$ and $v \leqslant w$, then $u \ll w$.

$\left(\mathrm{p}_{3}\right)$ If $u \ll v$ and $v \ll w$, then $u \ll w$.

$\left(\mathrm{p}_{4}\right)$ If $\theta \leqslant u \ll c$ for each $c \in \operatorname{int} P$, then $u=\theta$.

( $\left.\mathrm{p}_{5}\right)$ If $a \leqslant b+c$, for each $c \in \operatorname{int} P$, then $a \leqslant b$.

(p) If $E$ is a tvs cone metric space with a cone $P$, and if $a \leqslant \lambda a$, where $a \in P$ and $0 \leq$ $\lambda<1$, then $a=\theta$.

$\left(\mathrm{p}_{7}\right)$ If $c \in \operatorname{int} P, a_{n} \in E$ and $a_{n} \rightarrow \theta$ in locally convex Hausdorff tvs $E$, then there exists an $n_{0}$ such that, for all $n>n_{0}$, we have $a_{n} \ll c$.

In [11], the concept of a set-valued contraction of Mizoguchi-Takahashi type was introduced and a fixed point theorem in setting of a normal cone was proved. In this article, we prove the same theorem in the setting of a tvs-cone metric space. We generalize results of [11], by omitting the assumption of normality in the results, that is 
the normality of $P$ is not a necessary. We use only the definition of convergence in terms of the relation "«". The only assumption is that the interior of the cone $P$ in locally convex Hausdorff tvs $E$ is nonempty, so we neither use continuity of the vector metric $d$, nor Sandwich Theorem. In such a way, we generalize results of $[11,29,30]$.

\section{Main results}

Let $E$ be a locally convex Hausdorff tvs with its zero vector $\theta, P$ a proper, closed and convex pointed cone in $E$ with int $P \neq \varnothing$ and $\leqslant$ be a partial ordering with respect to $P$. Let $(X, d)$ be a tvs-cone metric space with a solid cone $P$ and let $\mathcal{A}$ be a collection of nonempty subsets of $X$. According to [11], we denote

$$
s(p)=\{q \in E: p \preccurlyeq q\}
$$

for $p \in E$, and

$$
s(a, B)=\bigcup_{b \in B} s(d(a, b))
$$

for $a \in X$ and $B \in \mathcal{A}$. For $A, B \in \mathcal{A}$, we denote

$$
s(A, B)=\left(\bigcap_{a \in A} s(a, B)\right) \cap\left(\bigcap_{b \in B} s(b, A)\right) .
$$

The following lemma will be used to prove Theorem 2.3 .

Lemma 2.1. Let $(X, d)$ be a tvs-cone metric space with a solid cone $P$ in ordered locally convex space $E$, and let $\mathcal{A}$ be a collection of nonempty subsets of $X$. Then we have:

(1) For all $p, q \in E$. If $p \leqslant q$, then $s(q) \subset s(p)$.

(2) For all $x \in X$ and $A \in \mathcal{A}$. If $\theta \in s(x, A)$, then $x \in A$.

(3) For all $q \in P$ and $A, B \in \mathcal{A}$ and $a \in A$. If $q \in s(A, B)$, then $q \in s(a, B)$.

(4) For all $q \in P$ and $A, B \in \mathcal{A}$. Then $q \in s(A, B)$ if and only if there exist $a \in A$ and $b \in B$ such that $d(a, b) \leqslant q$.

Remark 2.2. Let $(X, d)$ be a tvs-cone metric space. If $E=\mathbb{R}$ and $P=[0,+\infty)$, then $(X$, $d)$ is a metric space. Moreover, for $A, B \in C B(X), H(A, B)=\inf s(A, B)$ is the Hausdorff distance induced by $d$. Also, $s(\{x\},\{y\})=s(d(x, y))$, for all $x, y \in X$.

Now let us prove the following main results of this article.

Theorem 2.3. Let $(X, d)$ be a tvs-cone complete metric space with a solid cone $P, \mathcal{A} \neq \emptyset$ be a collection of nonempty closed subsets of $x$ and $T: X \rightarrow \mathcal{A}$ be a multivalued map. If there exists a function $\phi: P \rightarrow[0,1)$ such that

$$
\varlimsup_{n \rightarrow \infty} \varphi\left(c_{n}\right)<1
$$

for any decreasing sequence $\left\{c_{n}\right\}$ in $P$, and if

$$
\varphi(d(x, y)) d(x, y) \in s(T x, T y)
$$

for all $x, y \in X(x \neq y)$, then $T$ has a fixed point in $X$.

Proof. Let $x_{0} \in X, x_{1} \in T x_{0}$ and assume $x_{0} \notin T x_{0}$. Then from (2), we have

$$
\varphi\left(d\left(x_{0}, x_{1}\right)\right) d\left(x_{0}, x_{1}\right) \in s\left(T x_{0}, T x_{1}\right) .
$$


Now by Lemma 2.1(3), we have $\phi\left(d\left(x_{0}, x_{1}\right)\right) d\left(x_{0}, x_{1}\right) \in s\left(x_{1}, T x_{1}\right)$. By definition, we can take $x_{2} \in T x_{1}$ such that $\phi\left(d\left(x_{0}, x_{1}\right)\right) d\left(x_{0}, x_{1}\right) \in s\left(d\left(x_{1}, x_{2}\right)\right)$. So, $d\left(x_{1}, x_{2}\right) \leqslant \phi\left(d\left(x_{0}\right.\right.$, $\left.\left.x_{1}\right)\right) d\left(x_{0}, x_{1}\right)$.

Inductively, we can construct a sequence $\left\{x_{n}\right\}$ in $X$ such that for all $n \in \mathbb{N}$, we have

$$
d\left(x_{n}, x_{n+1}\right) \preccurlyeq \varphi\left(d\left(x_{n-1}, x_{n}\right)\right) d\left(x_{n-1}, x_{n}\right), x_{n+1} \in T x_{n} .
$$

If $x_{n}=x_{n+1}$ for some $n \in \mathbb{N}$, then $T$ has a fixed point.

We may assume that $x_{n} \neq x_{n+1}$, for all $n \in \mathbb{N}$. From (3), $\left\{d\left(x_{n}, x_{n+1}\right)\right\} \mathrm{s}$ a decreasing sequence in $P$. Hence, from (1), there exists $r \in 0,1)$ such that

$$
\varlimsup_{n \rightarrow \infty} \varphi\left(d\left(x_{n}, x_{n+1}\right)\right)=r .
$$

Thus, for any $\lambda \in(r, 1)$, there exists $n_{0} \in \mathbb{N}$ such that for all $n \geq n_{0}$, we have $\phi\left(d\left(x_{n}\right.\right.$, $\left.\left.x_{n+1}\right)\right)<\lambda$. Then we get, for $n \geq n_{0}$,

$$
d\left(x_{n}, x_{n+1}\right) \preccurlyeq \varphi\left(d\left(x_{n-1}, x_{n}\right)\right) d\left(x_{n-1}, x_{n}\right) \prec \lambda d\left(x_{n-1}, x_{n}\right) \prec \lambda^{n-n_{0}} d\left(x_{n_{0}}, x_{n_{0}+1}\right) .
$$

For $m>n \geq n_{0}$, we have

$$
\begin{aligned}
d\left(x_{n}, x_{m}\right) & \preccurlyeq d\left(x_{n}, x_{n+1}\right)+d\left(x_{n+1}, x_{n+2}\right)+\cdots+d\left(x_{m-1}, x_{m}\right) \\
& \preccurlyeq\left(\lambda^{n-n_{0}}+\lambda^{n+1-n_{0}}+\cdots+\lambda^{m-1-n_{0}}\right) d\left(x_{n_{0}}, x_{n_{0}+1}\right) \\
& \preccurlyeq \lambda^{n}\left[\frac{1}{\lambda^{n_{0}}(1-\lambda)}\right] d\left(x_{n_{0}}, x_{n_{0}+1}\right) .
\end{aligned}
$$

Since $\lambda^{n} \rightarrow 0$ as $n \rightarrow \infty$, we obtain that $\lambda^{n}\left[\frac{1}{\lambda^{n}(1-\lambda)}\right] d\left(x_{n_{0}}, x_{n_{0}+1}\right) \rightarrow \theta$ in the locally convex space $E$, as $n \rightarrow \infty$. Now, according to $\left(\mathrm{p}_{7}\right)$ and $\left(\mathrm{p}_{1}\right)$, we can conclude that for every $c \in E$ with $\theta \ll c$ there is a natural number $n_{1}$ such that $d\left(x_{n}, x_{m}\right) \ll c$ for all $m, n \geq \max \left\{n_{0}, n_{1}\right\}$, so $\left\{x_{n}\right\}$ is a tvs-cone Cauchy sequence. Since $(X, d)$ is tvs-cone complete, then $\left\{x_{n}\right\}$ is tvs-cone convergent in $X$ and cone- $\lim _{n \rightarrow \infty} x_{n}=x$, that is, for every $c \in E$ with $\theta \ll c$, there is a natural number $k$ such that $d\left(x_{n}, x\right) \ll c$ for all $n \geq$ $k$.

We now show that $x \in T x$. Indeed, from (2) we have $\phi\left(d\left(x_{n}, x\right)\right) d\left(x_{n}, x\right) \in s\left(T x_{n}\right.$, $T x)=s\left(x_{n+1}, T x\right)$ for $n \in \mathbb{N}$. By Lemma 2.1(3), there exists $y_{n} \in T x$ such that

$$
\varphi\left(d\left(x_{n}, x\right)\right) d\left(x_{n}, x\right) \in s\left(d\left(x_{n+1}, y_{n}\right)\right) .
$$

Hence, $d\left(x_{n+1}, y_{n}\right) \leqslant \phi\left(d\left(x_{n}, x\right)\right) d\left(x_{n}, x\right) \leqslant d\left(x_{n}, x\right)$. Moreover, for a given $c \in$ int $P$, we have

$$
\begin{aligned}
d\left(x, y_{n}\right) & \preccurlyeq d\left(x, x_{n+1}\right)+d\left(x_{n+1}, y_{n}\right) \\
& \preccurlyeq d\left(x, x_{n+1}\right)+d\left(x_{n}, x\right) \\
& \ll \frac{c}{2}+\frac{c}{2}=c, \text { for } n \geq k=k(c) .
\end{aligned}
$$

Hence, according to Definition 1.3(i), we have that cone- $\lim _{n \rightarrow \infty} y_{n}=x$. As $T x$ is closed, then $x \in T x$, hence $x$ is a fixed point of $T$ and this ends the proof. $\square$

The next example shows that Theorem 2.3 is a proper generalization of the main result from [11]. Indeed, as in Example 2.4, the cone $P$ is nonnormal, so Theorem 2.1 of [11] is not applicable. 
Example 2.4. Let $X=[0,1]$ and $E=C[0,1]$ be endowed with the strongest locally convex topology $\tau\left(E, E^{*}\right)$, and let $P=\{x \in E:, x(t) \geq 0, t 0[1]\}$. Then the cone $P$ is a normal cone with respect to the norm of the space $E$ with a coefficient of normality $K$ $=1$. Also, $P$ is a solid cone. Since $\tau\left(E, E^{*}\right)$ is stronger than a norm-topology, then the interior of $P$ is nonempty with respect to $\tau\left(E, E^{*}\right)$. Thus, $P$ is $\tau\left(E, E^{*}\right)$-solid. This cone is nonnormal with respect to the topology $\tau\left(E, E^{*}\right)$. Indeed, if it were normal, then according to Theorem 2.1 of [14], the space $(E, \tau(E, E))$ would be normed, which is impossible as an infinite-dimensional space with the strongest locally convex topology cannot be metrizable (see [31]). Let us define the tvs-cone metric with $d: X \times X \rightarrow E$, by $d(x, y)(t):=|x-y| e^{t}$. Let $\mathcal{A}$ be a family of nonempty closed subsets of $X$ of the form $\mathcal{A}=\{[0, x] ; x \in X\}$. Consider a mapping $T: X \rightarrow \mathcal{A}$ defined by $T(x)=\left[0, \frac{x}{3}\right]$. Let $\varphi(c)=\frac{1}{2}$ for all $c \in P$. Obviously, the hypothesis (1) is satisfied. We now show that (2) is also a satisfied. Moreover, for $x, y<X(x \neq y)$ we have,

$$
\begin{aligned}
\varphi(d(x, y)) d(x, y) & \in \quad s(T x, T y) \Leftrightarrow \frac{1}{2} d(x, y) \in s(T x, T y) \\
& \Leftrightarrow \quad \frac{1}{2} d(x, y) \in\left(\bigcap_{a \in T x b \in T_{y}} s(d(a, b))\right) \cap\left(\bigcap_{b \in T_{Y} a \in T x} s(d(a, b))\right) \\
& \Leftrightarrow \quad(\exists a \in T x)(\exists b \in T y) \frac{1}{2} d(x, y) \in s(d(a, b)) \\
& \Leftrightarrow \quad d(a, b) \preccurlyeq \frac{1}{2} d(x, y) .
\end{aligned}
$$

Now, taking $a=\frac{1}{3} x$, and $b=\frac{1}{3} y$, we obtain that the hypothesis (2) is satisfied. Hence using Theorem 2.3, it follows that $T$ has a fixed point.

Example 2.5. Let $E=C_{\mathbb{R}}^{1}[0,1]$ with a norm $\|u\|=\|u\|_{\infty}+\left\|u^{\prime}\right\|_{\infty}, u \in E$ and let $P=$ $\{u \in E: u(t) \geq 0, t \in 0[1]\}$. It is well known that this cone is solid but it is not normal. Now consider the space $E=C_{\mathbb{R}}^{1}[0,1]$ endowed with the strongest locally convex topology $t^{*}$. Then $P$ is also $t^{*}$-solid (it has nonempty $t^{*}$-interior), but not $t^{*}$-normal. (For more details, see [31], Example 2.2).

Let $X=\{a, b, c\}$ and define a tvs-cone metric $d: X \times X \rightarrow P$ by

$$
\begin{aligned}
& d(a, b)(t):=2+3 t, d(b, c)(t):=5-3 t, d(a, c)(t):=3, \\
& d(x, y)=d(y, x) \text { and } d(x, x)=\theta \text { for } x, y \in X .
\end{aligned}
$$

Then $(X, d)$ is a complete tvs-cone metric space over the nonnormal cone $P$. Now, consider the mapping $T: X \rightarrow X$ which is given by $T a=\{a, b\}, T b=\{a, c\}$ and $T c=$ $\{a, b, c\}$. Let $\varphi(c)=\frac{1}{2}$, for all $c \in P$. It is clear that the hypothesis (1) is satisfied. So let us prove that (2) is also satisfied, that is $\frac{1}{2} d(x, y) \in s(T x, T y)$, for all $x, y \in X(x \neq y)$. Now, we have the following:

$$
\begin{aligned}
& 1^{0} \frac{1}{2} d(a, b) \in s(T a, T b)=s(\{a, b\}, \quad\{a, c\}) \Leftrightarrow \exists a_{1} \in T a, \exists b_{1} \in T b \quad \text { such } \quad \text { that } \\
& d\left(a_{1}, b_{1}\right) \preccurlyeq \frac{1}{2} d(a, b) \text { Take } a_{1}=b_{1}=a ; \\
& 2^{0} \frac{1}{2} d(a, c) \in s(T a, T c)=s(\{a, b\}, \quad\{a, b, c\}) \Leftrightarrow \exists a_{2} \in T a, \exists b_{2} \in T c \quad \text { such } \quad \text { that } \\
& d\left(a_{2}, b_{2}\right) \preccurlyeq \frac{1}{2} d(a, b) \text {. Take } a_{2}=b_{2}=a ;
\end{aligned}
$$


$3^{0} \frac{1}{2} d(a, b) \in s(T b, T c)=s(\{a, c\}, \quad\{a, b, c\}) \Leftrightarrow \exists a_{3} \in T b, \exists b_{3} \in T c$ such $\quad$ that $d\left(a_{3}, b_{3}\right) \preccurlyeq \frac{1}{2} d(a, b)$. Take $a_{3}=b_{3}=a$.

Therefore, all conditions of Theorem 2.3 are satisfied and hence $T$ has a fixed point. Precisely, $x=a$ and $x=c$ are the fixed points of $T$.

Finally, we finish our paper by introducing the following consequence corollaries of our main theorem. let $(X, d)$ be a given metric space, and let us define the following:

- $C B(X)=\{A: A$ is a nonempty closed and bounded subset of $X\}$,

- $D(a, B)=\inf \{d(a, b): b \in B \cdot X\}$, for $a \in X$,

- $H(A, B)=\max \{\sup \{D(a, B): a \in A\}, \sup \{D(b, A): b \in B\}\}$.

It is clear that $H$ is a metric on $C B(X)$, which is called the Hausdorff-Pompeu metric induced by $d$. A set-valued mapping $T: X \rightarrow C B(X)$ is said to be a multi-valued contraction mapping, if there exists a fixed real number $\lambda, 0 \leq \lambda<1$ such that,

$$
H(T x, T y) \leq \lambda d(x, y),
$$

for all $x, y \in X$. A point $x \in X$ is called a fixed point of $T$, if $x \in T x$. Then as a consequence of Theorem 2.3 and in particular by taking $E=\mathbb{R}, P=[0,+\infty), \mathcal{A}=C B(X), \phi$ $(c)=\lambda$, for all $c \in P$, we obtain the following corollary.

Corollary 2.6. (Nadler [30]) Let $(X, d)$ be a complete metric space and let $T: X \rightarrow$ $C B(X)$ be a multi-valued contraction mapping. Then $T$ has a fixed point.

Also, according to Remark 2.2, we obtain the following corollary.

Corollary 2.7. (Mizoguchi-Takahashi [29]) Let $(X, d)$ be a complete metric space and let $T: X \rightarrow 2^{X}$ be a multi-valued mapping such that, Tx is a closed bounded subset of $X$, for all $x \in X$. If there exists a function $\phi:[0,+\infty) \rightarrow[0,1)$ such that,

$$
\varlimsup_{r \rightarrow t+} \varphi(r)<1 \text { for all } t \in[0,+\infty)
$$

and if

$$
H(T x, T y) \leq \varphi(d(x, y)) d(x, y)
$$

for all $x, y \in X(x \neq y)$, then $T$ has a fixed point in $X$.

\section{Acknowledgments}

The authors would like to thank the referee and the editor for their valuable comments and suggestions. Vesna Cojbašić Rajić and Stojan Radenović are thankful to the Ministry of Science and Technological Development of Serbia

\section{Author details}

'Department of Mathematics, Hashemite University Zarqa, Jordan ${ }^{2}$ University of Belgrade, Faculty of Economics, Kamenička 6, 11000 Beograd, Serbia ${ }^{3}$ University of Belgrade, Faculty of Mechanical Engineering, Kraljice Marije 16, 11 120 Beograd, Serbia ${ }^{4}$ Department of Mathematical Sciences, UAEU, 17551 Al-Ain, United Arab Emirates

Authors' contributions

All the authors contributed equally. All authors read and approved the final manuscript.

Competing interests

The authors declare that they have no competing interests. 


\section{References}

1. Huang, LG, Zhang, X: Cone metric spaces and fixed point theorems of contractive mappings. J Math Anal Appl. 332(2), 1468-1476 (2007). doi:10.1016/j.jmaa.2005.03.087

2. Al-Rawashdeh, A, Shatanawi, W, Khandaqji, M: Normed ordered and E-mertic spaces. Int J Math Math Sci 11 (2012). Article ID 272137, doi:10.1155/2012/272137

3. Abbas, M, Cho, YJ, Nazir, T: Common fixed point theorems for four mappings in TVS-valued cone metric spaces. J Math Inequal. 5, 287-299 (2011)

4. Abbas, M, Vetro, P, Khan, SH: On fixed points of Berinde's contractive mappings in cone metric spaces. Carpathian J Math. 26, 121-133 (2010)

5. Abdeljawad, T, Karapinar, E, Taş, K: Common fixed point theorems in cone banach spaces. Hacettepe J Math Stat. 40, 211-217 (2011)

6. Abdeljawad, T: Completion of TVS-cone metric spaces and some fixed point theorems. Gazi Univ J Sci. 24, 235-240 (2011)

7. Azam, A, Beg, I, Arshad, M: Fixed point in topological vector space-valued cone metric spaces. Fixed Point Theory Appl 2010, 9 (2010). Article ID 604084, doi:10.1155/2010/604084

8. Amini-Harandi, A, Fakhar, M: Fixed point theory in cone metric spaces obtained via the scalarization method. Comput Math Appl. 59, 3529-3534 (2010). doi:10.1016/j.camwa.2010.03.046

9. Beg, I, Azam, A, Arshad, M: Common fixed points for maps on topological vector space valued cone metric spaces. Int J Math Math Sci 2009, 8 (2009). Article ID 560264

10. Cvetković, AS, Stanić, MP, Dimitrijević, S, Simić, S: Common fixed point theorems for four mappings on cone metric type space. Fixed Point Theory Appl 2011 (2011). Article ID 589725

11. Cho, SH, Bae, JS: Fixed point theorems for multi-valued maps in cone metric spaces. Fixed Point Theory Appl 2011, 87 (2011). doi: 10.1186/1687-1812-2011-87. doi:10.1186/1687-1812-2011-87

12. Dordević, M, Dorić, D, Kadelburg, Z, Radenović, S, Spasić, D: Fixed point results under c-distance in tvs-cone metric spaces. Fixed Point Theory Appl 2011, 29 (2011). doi:10.1186/1687-1812-2011-29. doi:10.1186/1687-1812-2011-29

13. Du, WS: A note on cone metric fixed point theory and its equivalence. Nonlinear Anal. 72, 2259-2261 (2010). doi:10.1016/j.na.2009.10.026

14. Kadelburg, Z, Radenović, S, Rakočević, V: Topological vector space valued cone metric spaces and fixed point theorems. Fixed Point Theory Appl 2010, 17 (2010). Article ID 170253. doi: 10.1155/2010/170253

15. Kadelburg, Z, Radenović, S, Rakočević, V: A note on equivalence of some metric and cone metric fixed point results. Appl Math Lett. 24, 370-374 (2011). doi:10.1016/j.aml.2010.10.030

16. Kadelburg, Z, Radenović, S: Some results on set-valued contractions in abstract metric spaces. Comput Math Appl. 62 342-350 (2011). doi:10.1016/j.camwa.2011.05.015

17. Karapinar, E, Yüksel, U: On common fixed point theorems without commuting conditions in TVS-cone metric spaces. Comput Anal Appl. 13, 1115-1122 (2011)

18. Karapinar, E: Couple fixed point on cone metric spaces. Gazi Univ J Sci. 24, 51-58 (2011)

19. Karapinar, E, Türkoğlu, D: Best approximations theorem for a couple in cone Banach space. Fixed Point Theory Appl 2010 (2010). Article ID 784578 (2010)

20. Karapinar, E: Some nonunique fixed point theorems of Ćirić Type on Cone Metric Spaces. Abstr Appl Anal 2010 (2010). Article ID 123094

21. Klim, D, Wardowski, D: Dynamic processes and fixed points of set-valued nonlinear contractions in cone metric spaces. Nonlinear Anal. 71, 5170-5175 (2009). doi:10.1016/j.na.2009.04.001

22. Radenović, S, Simić, Su, Cakić, N: Zorana Golubović. A note on tvs-cone metric fixed point theory. Math Comput Model. 54, 2418-2422 (2011). doi:10.1016/j.mcm.2011.05.051

23. Shatanawi, W: Some coincidence point results in cone metric spaces. Math Comput Model (2011). doi:10.1016/j. mcm.2011.11.061

24. Shatanawi, W: On $W$-compatible mappings and common coupled coincidence point in cone metric spaces. Appl Math Lett (2011). doi:10.1016/j.aml.2011.10.037

25. Shatanawi, W: Some common coupled fixed point results in cone metric spaces. Int J Math Anal. 4, $2381-2388$ (2010)

26. Turkoglu, D, Abuloha, M, Abdeljawad, T: Fixed points of generalized contraction mappings in cone metric spaces. Math Commun. 16, 325-334 (2011)

27. Turkoglu, D, Abuloha, M, Abdeljawad, T: KKM mappings in cone metric spaces and some fixed point theorems. Nonlinear Anal Theory Methods Appl. 72, 348-353 (2010). doi:10.1016/j.na.2009.06.058

28. Wardowski, D: On set-valued contractions of Nadler type in cone metric spaces. Appl Math Lett. 24, 275-278 (2011). doi:10.1016/j.aml.2010.10.003

29. Mizoguchi, N, Takahashi, W: Fixed point theorems for multi-valued mappings on complete metric spaces. J Math Anal Appl. 141, 177-188 (1989). doi:10.1016/0022-247X(89)90214-X

30. Nadler, JrSB: Multi-valued contraction mappings. Pac J Math. 30, 475-488 (1969)

31. Schaefer, HH: Topological Vector Spaces, 3rd edn.Springer, New York (1971)

doi:10.1186/1687-1812-2012-106

Cite this article as: Shatanawi et al:: Mizoguchi-Takahashi-type theorems in tvs-cone metric spaces. Fixed Point

Theory and Applications 2012 2012:106 